\title{
The impact of an innovative curriculum to introduce patient safety and quality improvement content
}

\author{
Kelly T. Gleason ${ }^{*}$, Brigit VanGraafeiland ${ }^{1}$, Yvonne Commodore-Mensah', Jo Walrath', Susan Immelt', \\ Ellen Ray ${ }^{2}$ and Cheryl R. Dennison Himmelfarb ${ }^{1}$
}

\begin{abstract}
Background: The Fuld Fellows Program provides selected pre-licensure nursing students with a foundation in the science of patient safety, quality improvement and leadership through coursework and a mentored experience working on a quality improvement project. We evaluated this program's impact on Fellows' patient safety competence and systems thinking.

Methods: Cohorts I-VI $(n=116)$ completed pre-post program evaluation that included measurement of patient safety competence through the Health Professional Education in Patient Safety Survey (H-PEPSS) and systems thinking using the Systems Thinking Scale. Pre- and post-program H-PEPSS and Systems Thinking Scale scores were compared using the Wilcoxon Signed-Rank Test. The Fellows were compared to non-Fellows on patient safety competence and systems thinking using t-tests.

Results: Patient safety competence on all H-PEPSS scales improved from baseline to end of program: teamwork (2.6 to 3.1), communication (2.1 to 3.2), managing risk (2.2 to 3.3), human environment (2.8 to 3.7), recognize and respond to risk ( 2.7 to 3.6$)$, and culture ( 2.9 to 3.8$)(p<0.05)$. The Fellows, in comparison to the non-Fellows, reported a significantly higher $(p<0.05)$ mean change score in five of the six H-PEPSS subscales. Fellows' mean systems thinking score increased from $66 \pm 7$ at baseline to $70 \pm 6$ at program completion $(p<0.05)$, this mean post completion score was significantly higher than the non-Fellows reported mean STS score of $62 \pm 7$.

Conclusion: The Fuld Fellows Program effectively facilitated patient safety and quality improvement and systems thinking learning among pre-licensure nursing students. This program can serve as a model for integrating quality and safety concepts into health professionals' curricula.
\end{abstract}

\section{Background}

In response to complex healthcare challenges in the United States, there is an urgent call for health professionals' education to include development of patient safety and quality improvement competencies [1-3]. Despite the clear need, patient safety content continues to be insufficiently delivered across health professionals' curricula $[4,5]$. Adding patient safety content into curricula has several implementation challenges, including the lack of faculty prepared to teach such courses [6,7], the limited available time in curricula [7, $8]$, and the increased amount of instructing done through

\footnotetext{
* Correspondence: kgleaso2@jhmi.edu

${ }^{1}$ School of Nursing, Johns Hopkins University, 525 N Wolfe Street, Baltimore, MD 21205, USA

Full list of author information is available at the end of the article
}

simulation leaving less time to apply patient safety content in practical situations. The Essentials of Baccalaureate Education for Professional Nursing Practice state that nurses prepared in master's nursing programs must develop skills to articulate methods, tools, performance measures, and standards related to quality, and be prepared to apply quality principles within an organization [9], highlighting the need for schools of nursing to meaningfully include quality improvement education in nursing curricula.

Nurses play key roles and demonstrate great success in leading efforts to improve quality of care and patient safety [10-15]. However, nursing students report a lack of understanding of patient safety principles and feeling incompetent in patient safety matters [16]. There is a paucity of nursing literature discussing a longitudinal curriculum for quality 
improvement and patient safety content in pre-licensure nursing curricula [17]. A review of patient safety learning identified that patient safety was often not clearly and explicitly taught as a subject in the nursing curricula $[7,16]$, and a lack evidence on which clinical learning environments facilitate the development of patient safety competencies in pre-licensure nursing students [18].

The Helene Fuld Leadership Program for the Advancement of Patient Care Quality and Safety (The Fuld Fellows Program) at the Johns Hopkins University School of Nursing is designed to address this gap in nursing education. The program prepares a select group of pre-licensure nursing students for future leadership at the bedside and in other care settings, who have exceptional competencies for promoting quality and safety. It focuses on the following objectives from the The Essentials of Baccalaureate Education for Professional Nursing Practice: 1) Demonstrate leadership and communication skills to effectively implement patient safety and quality improvement initiatives within the context of the interprofessional team, 2) Apply concepts of quality and safety using structure, process, and outcome measures to identify clinical questions and describe the process of changing current practice, and 3) Apply concepts of quality and safety using structure process, and outcomes measures to identify clinical questions and describe the process of changing current practice [9].

The purpose of this paper is to describe the Fuld Fellows Program and to answer the research question: Does participating in the Fuld Fellows Program increase Fellows' perceived patient safety competencies and Systems Thinking? We hypothesized that Fellows' perceived patient safety competencies and Systems Thinking would increase after participating in the Fuld Fellows Program, and that this increase would be significantly higher than students who did not participate. We also describe fellow and mentor satisfaction with the program.

\section{Methods}

\section{Program description}

The Fuld Fellows Program provides selected students with: 1) a broad, evidence-based, quality improvement and patient safety interprofessional education; 2) practical quality and patient safety learning experiences with Johns Hopkins improvement teams; and, 3) mentoring to bridge theory and practice. The program consists of 4 courses taken in parallel to the pre-licensure curriculum, a 3-day interprofessional intersession course, and a 6 month experience working with a quality improvement project (Table 1). Fellows who display a special interest in developing quality and safety skills beyond those standard curriculum are selected.

The first semester course applies a systems approach introducing the Fellows to the science of patient safety and quality improvement. Using case studies, case-based quizzes and peer assessments, the course prepares Fellows with basic knowledge and skills necessary for their work with a clinical project team. Fellows work 50 -h per semester in semesters two and three with a mentor and

Table 1 Fuld Fellowship Curriculum

\begin{tabular}{|c|c|c|}
\hline Semester & Course Content & Evaluations \\
\hline $\begin{array}{l}\text { Pre- } \\
\text { Semester }\end{array}$ & & Systems Thinking Scale \\
\hline 1 & $\begin{array}{l}\text { 1) Overview of science of safety and an introduction to a culture of safety in } \\
\text { healthcare } \\
\text { 2) Explores enabling and contextual factors, including communication, teamwork, and } \\
\text { human factors, that influence safety and quality } \\
\text { 3) Introduces multiple methods to improve safety and quality, including } \\
\text { Comprehensive Unit-Based Safety Program, disclosing adverse events, learning from } \\
\text { defects, and patient-centered care } \\
\text { 4) Translating evidence into practice/leading change } \\
\text { 5) Capacity building for improved patient safety and quality }\end{array}$ & \\
\hline $\begin{array}{l}2 \\
3\end{array}$ & $\begin{array}{l}\text { 1) Experiential learning working on a mentored quality improvement project ( } 50 \mathrm{~h} \text { a } \\
\text { semester for } 2 \text { semesters) } \\
\text { 2) Monthly seminar to review and reinforce key patient safety \& quality concepts }\end{array}$ & \\
\hline $\begin{array}{l}\text { Post- } \\
\text { Semester } 3\end{array}$ & & Mentor/Mentee Satisfaction \\
\hline 4 & $\begin{array}{l}\text { 1) Leadership to improve safety in complex systems } \\
\text { 2) Advocacy for patients, families, and colleagues } \\
\text { 3) Prepare and present scientific poster disseminating results of mentored quality } \\
\text { improvement project }\end{array}$ & \\
\hline $\begin{array}{l}\text { Post- } \\
\text { Semester } 4\end{array}$ & & $\begin{array}{l}\text { Focus group, Systems Thinking Scale, and } \\
\text { Health Professional Education in Patient } \\
\text { Safety Survey }\end{array}$ \\
\hline $\begin{array}{l}1 \text { Year Post- } \\
\text { Fellowship }\end{array}$ & & $\begin{array}{l}\text { Health Professional Education in Patient } \\
\text { Safety Survey }\end{array}$ \\
\hline
\end{tabular}


interprofessional, patient safety or quality improvement team in a Johns Hopkins clinical setting. In addition, they participate in bi-weekly, online reflective learning journals focusing on specific attributes of safe, high reliability healthcare delivery teams. In the fourth and final semester, Fellows create a scholarly poster presentation and disseminate their project-based learning. The coursework in this final semester focuses on providing realistic and practical approaches for translating Fuld learning in quality and safety into the clinical work settings the Fellows are preparing to enter. Fellows have an opportunity to participate in a 3-day interprofessional patient safety simulation course that includes nursing and medical students taught by interprofessional faculty. This course focuses on improving students' teamwork and communication skills and system-based thinking and addresses the causes of preventable harm and evidence-based strategies for harm prevention. Cohorts I-VI $(n=115)$ have completed the program and evaluations as of December 2015. The Fuld Fellows Program continues and has been adapted for delivery in the new Master's Entry to Nursing Program is currently educating the twelfth cohort of students. Institutional Review Board approval (00087543) was obtained to evaluate the effectiveness of the program.

\section{Evaluation}

Process evaluation includes specific questions about course content, delivery, and attainment of learning goals for each course and at the end of program. Project mentor and Fellow evaluate each other in the middle and at the end of the program. Focus groups are conducted at the completion of the program. Pre-post program evaluation includes Fellows' perceptions of patient safety competence at entry into practice, using the Health Professional Education in Patient Safety Survey (H-PEPSS), and systems thinking, using the Systems Thinking Scale (STS) [19]. The pre-licensure nursing students who did not participate in the Fuld Fellows Program also complete the H-PEPSS survey and STS at the completion of the program to allow for post-program comparison across groups.

H-PEPSS measures self-reported patient safety competence through focusing on six domains of safety competencies: culture of safety, working in teams with other healthcare providers, effective communication, managing risk, optimizing human and environmental factors, and recognizing and responding to adverse events to measure patient safety learning [20]. H-PEPSS consists of 16 items and responses are measured in a 5-point disagree-agree Likert type scale. The items begin with 'I feel confident in what I learned about ... ' and include a 'don't know' option. Previous studies assessed the H-PEPSS validity and found that the Cronbach's alpha score ranges from 0.81 to 0.85 for all six domains [20]. For each item, the participants were asked to separately respond with their level of agreement before the program and after completion of the program.
The STS is a 20 -item instrument that evaluates participants' systems thinking in quality improvement work, such as "I think recurring patterns are more important than any one specific event" and "I consider the relationships among co-workers in the work unit." The STS measures items on a 5-point Likert-type scale and are scored 0 to 4 . The total score can range from 0 to 80 and is created by calculating the sum of the responses for each item. The STS is a validated scale with a Cronbach's alpha score of 0.89 [19].

A quasi-experimental design was used to compare Fellows to students who were not involved in the program for cohorts III through V. The Fellows in cohorts III through $\mathrm{V}$ were compared to their colleagues on outcomes of patient safety competence and systems thinking. This evaluation occurred at the time of their graduation from the pre-licensure nursing program.

Stata version 15 (StataCorp LP, College Station, TX was used for all analyses. Pre- and post- program scores for the H-PEPSS subscales and STS were compared using the Wilcoxon match-pairs signed-rank test for the participants who completed both the pre- and post-surveys. Pre-Post change scores were calculated and mean change scores for Fuld Fellows and non-Fuld Fellows were compared using t-tests. The Fuld Fellows and non-Fuld Fellows' post-program STS scores were compared using t-tests. Student and mentor satisfaction with the program was analyzed through descriptive statistics.

\section{Results}

The majority of the Fellows from Cohorts I-VI were female (87\%) and between the ages of 23-29 (81\%) (Table 2). The highest degree earned prior to entry to the program was a Bachelor's for the majority of the Fellows (81\%). The three most common pre-nursing fields of study were biology and health sciences (34\%), psychology (15\%), and anthropology (8\%). Thirty percent of the Fellows reported prior participation in patient safety projects. Most of the mentors had at least a Masters degree and held positions of leadership at Johns Hopkins. The setting of the projects varied significantly (Table 3), which gave the Fellows an opportunity to choose projects best-suited to their interests.

\section{Perceptions of patient safety competencies}

The Fellows in cohorts II through VI completed the H-PEPPS survey $(n=52)$. The Fellows' mean scores on the H-PEPSS scale improved from baseline to the completion of the program. Mean deviation scores on the H-PEPSS scales improved from baseline to end of program as follows: teamwork (2.6 to 3.1), communication (2.1 to 3.2), managing risk (2.2 to 3.3), human environment (2.8 to 3.7 ), recognize and respond to risk (2.7 to 3.6), and culture (2.9 to 3.8$)(p<0.001$ for all). Mean deviation scores on the H-PEPSS scales continued to improve 12 months following the program. 
Table 2 Description of Fuld Fellows

\begin{tabular}{ll}
\hline & Participants (Cohorts I-VI) \\
& $N=116$ \\
\hline Sex & $89 \%(104)$ \\
Age at program entry & \\
$22-29$ & $84 \%(98)$ \\
$30-39$ & $12 \%(14)$ \\
$40-49$ & $4 \%(5)$ \\
Highest Degree & \\
Bachelor's & $83 \%(96)$ \\
Masters & $15 \%(18)$ \\
JD & $1 \%(1)$ \\
PhD & $1 \%(1)$ \\
Pre-Nursing Field of Study & \\
Biology and health sciences & $31 \%(36)$ \\
Psychology & $16 \%(19)$ \\
Anthropology & $7 \%(8)$ \\
Sociology & $4 \%(5)$ \\
Other & $41 \%(48)$ \\
\hline
\end{tabular}

Compared to immediate post-program scores, there was an increase in teamwork (1.0), communication (1.0), managing risk (0.8), human environment (0.9), recognize and respond to risk (0.7), and culture (0.7). The increase in recognize and respond to risk and culture was significant $(p<0.05)$.

\section{Systems thinking in quality improvement}

The Fellows in cohorts I and III through VI completed the STS $(n=65)$. The mean scores on the STS improved from baseline to completion of the program in each of the cohorts. Mean \pm standard deviation scores on the systems thinking scale increased from $66.1 \pm 7.1$ at baseline to $70.3 \pm 6.4(p<0.001)$.

\section{Comparison to non-fellows}

Both the Fellows $(n=36)$ and non-Fellows $(n=37)$ who participated in the evaluation reported a significant increase $(p<0.001)$ across all six domains of patient safety competencies. The Fellows reported a significantly higher $(p<0.05)$ mean change score in comparison to the non-Fellows in five of the six domains of safety competencies: effective communication, working in teams with other healthcare providers, optimizing human and environmental factors, and culture of safety (Fig. 1). The Fellows reported a higher, but not statistically significant, mean change score in the domain of recognizing and responding to adverse events. The Fellows reported a mean STS score of $70.73 \pm 5.96$; this score was significantly higher $(p<0.001)$ than the non-Fellows reported mean STS score of $61.63 \pm 7.43$ (Fig. 2).

\section{Fellow and Mentor evaluations}

The results of the evaluations indicate that most Fellows and mentors found their relationship rewarding (Fig. 3). Also, $92 \%$ of the Fellows agreed or strongly agreed that

Table 3 Examples of Mentors and Projects

\begin{tabular}{|c|c|c|c|}
\hline Project Title & $\begin{array}{l}\text { Project } \\
\text { Setting }\end{array}$ & $\begin{array}{l}\text { Project } \\
\text { Category }\end{array}$ & Mentor Role \\
\hline $\begin{array}{l}\text { Perioperative Anti-Platelet and Anticoagulation Management Task Force Tar- } \\
\text { geted at reducing readmissions in the Department of Medicine }\end{array}$ & $\begin{array}{l}\text { Peri-operative } \\
\text { care }\end{array}$ & $\begin{array}{l}\text { Readmission } \\
\text { reduction }\end{array}$ & $\begin{array}{l}\text { Professor of Anesthesiology/Critical } \\
\text { Care Medicine }\end{array}$ \\
\hline Nursing Role and Work Flow Assessment & Inpatient & $\begin{array}{l}\text { Safe Nursing } \\
\text { Practice }\end{array}$ & $\begin{array}{l}\text { Senior Director of Nursing of } \\
\text { Ambulatory Services }\end{array}$ \\
\hline Rapid Access to Tertiary Care: A Clinical, Financial and Operational Model & $\begin{array}{l}\text { Emergency } \\
\text { care }\end{array}$ & Disaster care & Assistant Director of Nursing \\
\hline Early Sepsis Management & $\begin{array}{l}\text { Intensive Care } \\
\text { Unit }\end{array}$ & $\begin{array}{l}\text { Sepsis } \\
\text { management }\end{array}$ & Clinical Nurse Specialist \\
\hline $\begin{array}{l}\text { Prevention for Positives (Healthy Prevention Behaviors for HIV Positive } \\
\text { Patients) }\end{array}$ & Outpatient & $\begin{array}{l}\text { Health } \\
\text { Prevention }\end{array}$ & Nurse Manager \\
\hline Reducing Avoidable Hospitalizations & Outpatient & $\begin{array}{l}\text { Readmission } \\
\text { reduction }\end{array}$ & $\begin{array}{l}\text { VP/COO \& Sr. Director Quality/Safety, } \\
\text { Johns Hopkins Home Care Group }\end{array}$ \\
\hline Implementing the Central Line Checklist in the Operating Room & $\begin{array}{l}\text { Operating } \\
\text { Room }\end{array}$ & $\begin{array}{l}\text { Infection } \\
\text { prevention }\end{array}$ & Director of Nursing \\
\hline Reducing length of stay for Hospitalist patients & Inpatient & LOS reduction & Senior Director of Quality \\
\hline Evolution in postoperative Pain management & Surgery & $\begin{array}{l}\text { Pain } \\
\text { management }\end{array}$ & $\begin{array}{l}\text { Associate professor of } \\
\text { anesthesiology and critical care }\end{array}$ \\
\hline $\begin{array}{l}\text { Implementation of a Transitional care unit for the Department of } \\
\text { Neurosciences }\end{array}$ & $\begin{array}{l}\text { Post } \\
\text { Anesthesia } \\
\text { Care Unit }\end{array}$ & Implementation & Director of Nursing \\
\hline $\begin{array}{l}\text { Investigation of Potential Safety Issues with Acetaminophen use in Surgical } \\
\text { Patients }\end{array}$ & Surgery & $\begin{array}{l}\text { Medication } \\
\text { Safety }\end{array}$ & $\begin{array}{l}\text { Education Lead, Department of } \\
\text { Surgery }\end{array}$ \\
\hline
\end{tabular}




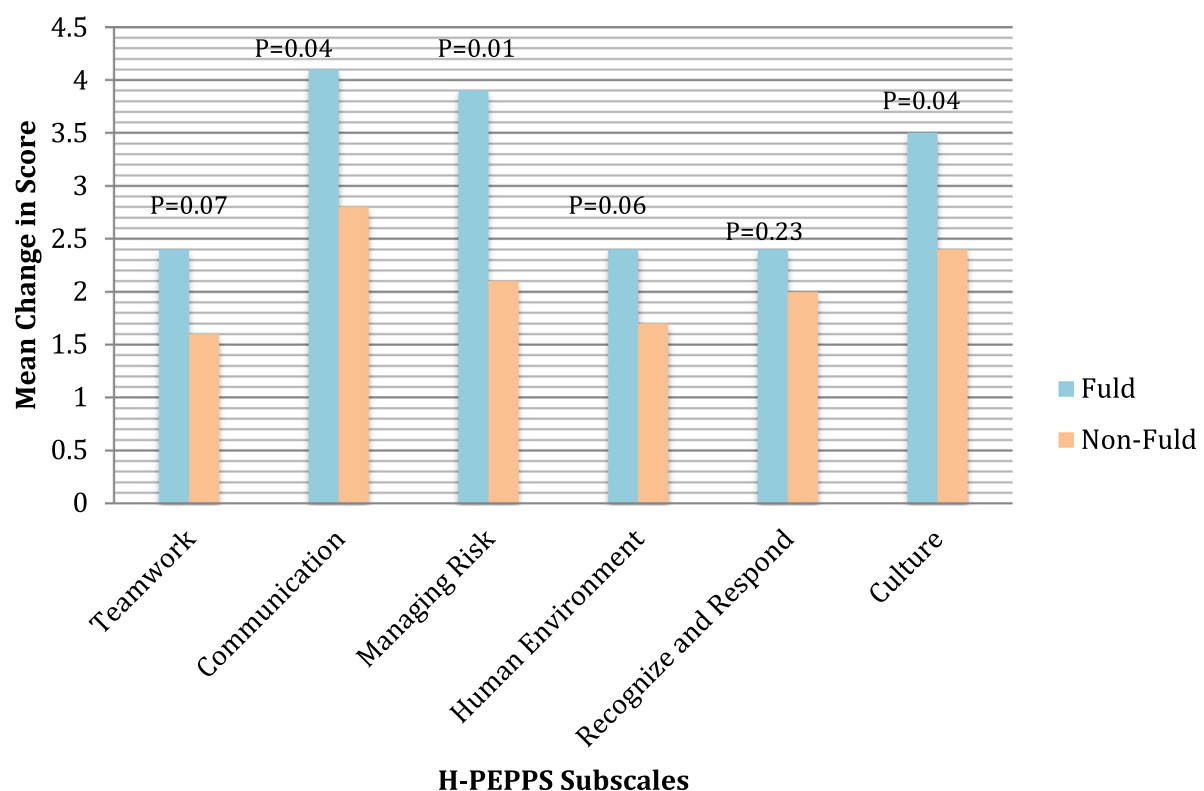

H-PEPPS Subscales

Fig. 1 Patient Safety Competency at Entry into Practice: Comparing Mean Change for Fuld and Non-Fuld Students

the relationship was successful, and $90 \%$ agreed and or strongly agreed that their mentors fostered their professional development. Furthermore, 93\% of the mentors who completed the evaluations agreed or strongly agreed that the experience was satisfying and $94 \%$ agreed or strongly agreed that the Fellows' progress in meeting the agreed upon the project goals met their expectations.

\section{Focus group results}

In the focus groups, the Fellows emphasized the value of exposure to patient safety and quality improvement education and hands-on projects. One Fellow stated: "I believe I will be more aware of quality improvement and safety issues and this will make me a leader in the workforce." Fellows who participated in the interprofessional education opportunity reported that it was a highlight of their Bachelor of Science in Nursing program and that they felt well-prepared to contribute to the interprofessional quality improvement case studies. Fellows gave feedback that they were excited to apply their knowledge as they embarked on their nursing careers and planned to be involved in patient safety and quality improvement projects in their future workplaces.

\section{Discussion}

Educating health professionals on the fundamentals of patient safety and quality improvement is essential to advancing a culture of safety within an increasingly complex and dynamic health care system [1]. The Fuld Fellows Program addresses the need for this education through: 1) didactic classes throughout the program dedicated to patient safety and quality improvement concepts, 2) an academic-clinical partnership that provides the Fellows with an opportunity to work in a clinical setting with a quality improvement team and, 3) an interprofessional course. The Fellows' perceived patient safety competencies and Systems Thinking significantly increased after participating in the program, and this increase was greater than students who did not participate. This program serves as a model for meaningfully including patient safety content in health professionals' education.

The Fuld Fellows Program runs parallel to the pre-licensure program, which provides Fellows with continuing content of patient safety concepts as their learning progresses. Previous work showed nursing students' lack of self-reported confidence in their knowledge of patient safety $[16,17]$. The ongoing connections built between safety concepts and practice through journaling and discussion with mentors and faculty may explain the improvement in perceptions of patient safety competence and in systems thinking across the four semesters.

Students' confidence in their understanding of patient safety declines as they advance in their academic program and become more exposed to the complexities of health care [21]. Results of a study where the HPEPSS was administered annually over 4 years suggest that confidence in the clinical dimensions of patient safety improve in the first 2 years of nursing school then decline in the second 2 years [21]. The authors also found that students' confidence in speaking up about patient safety issues declined as they gained experience in clinical settings. There is a great need for nurses to enter into practice prepared to professionally communicate about potential safety risks [22]. We hypothesized that Fellows' ongoing connections with Fuld faculty and with supportive mentors in leadership patient safety positions may explain why their confidence not only did not decrease, but actually 


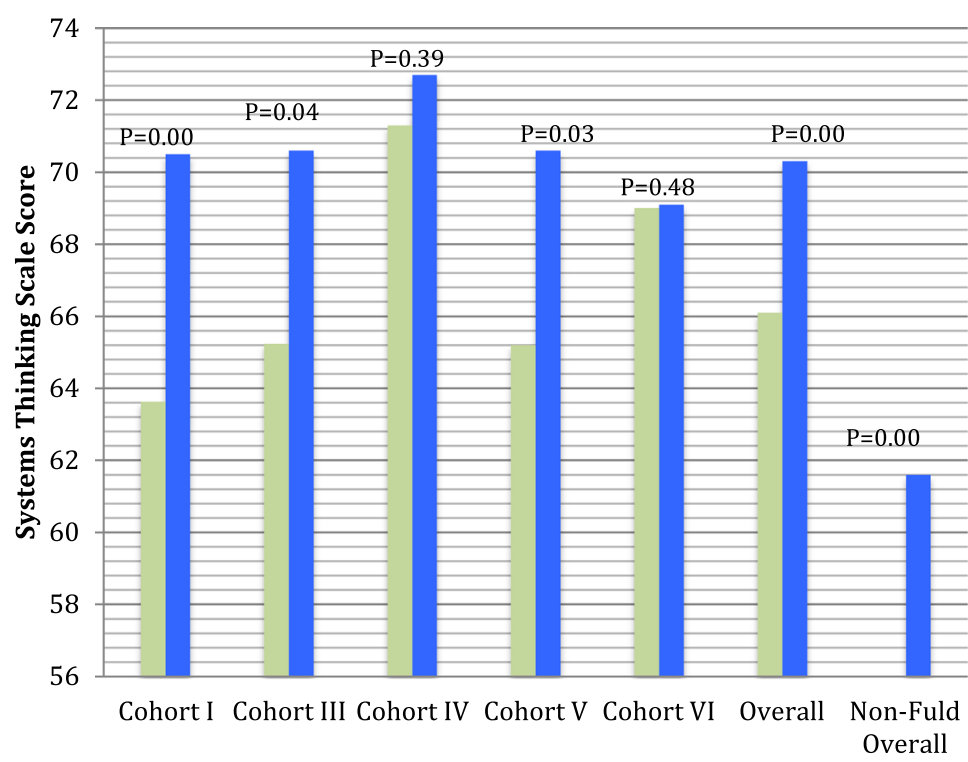

- Pre-Program

- Post-Program

Fuld Cohort

Fig. 2 Results of System Thinking Scale

increased, as shown by the results from the same instrument (HPEPSS). Qualitative results of focus groups confirm this impression. The Fellows perceived the Fuld Fellows Program as a distinct part of their experience at Johns Hopkins. The experiential learning enabled the Fellows to understand the challenges of implementing change in real clinical settings. Several Fellows described their participation in the Fuld Fellows Program as an advantage over non-participants. In addition, they saw their relationships with their mentors as supportive and contributory to their abilities to continue as leaders in patient safety following graduation. This was the goal of the Fuld Fellows Program.

Interprofessional education is required by licensing bodies of health professions and this includes understanding the roles and responsibilities of both professions, engaging in effective communication, collaborating around shared

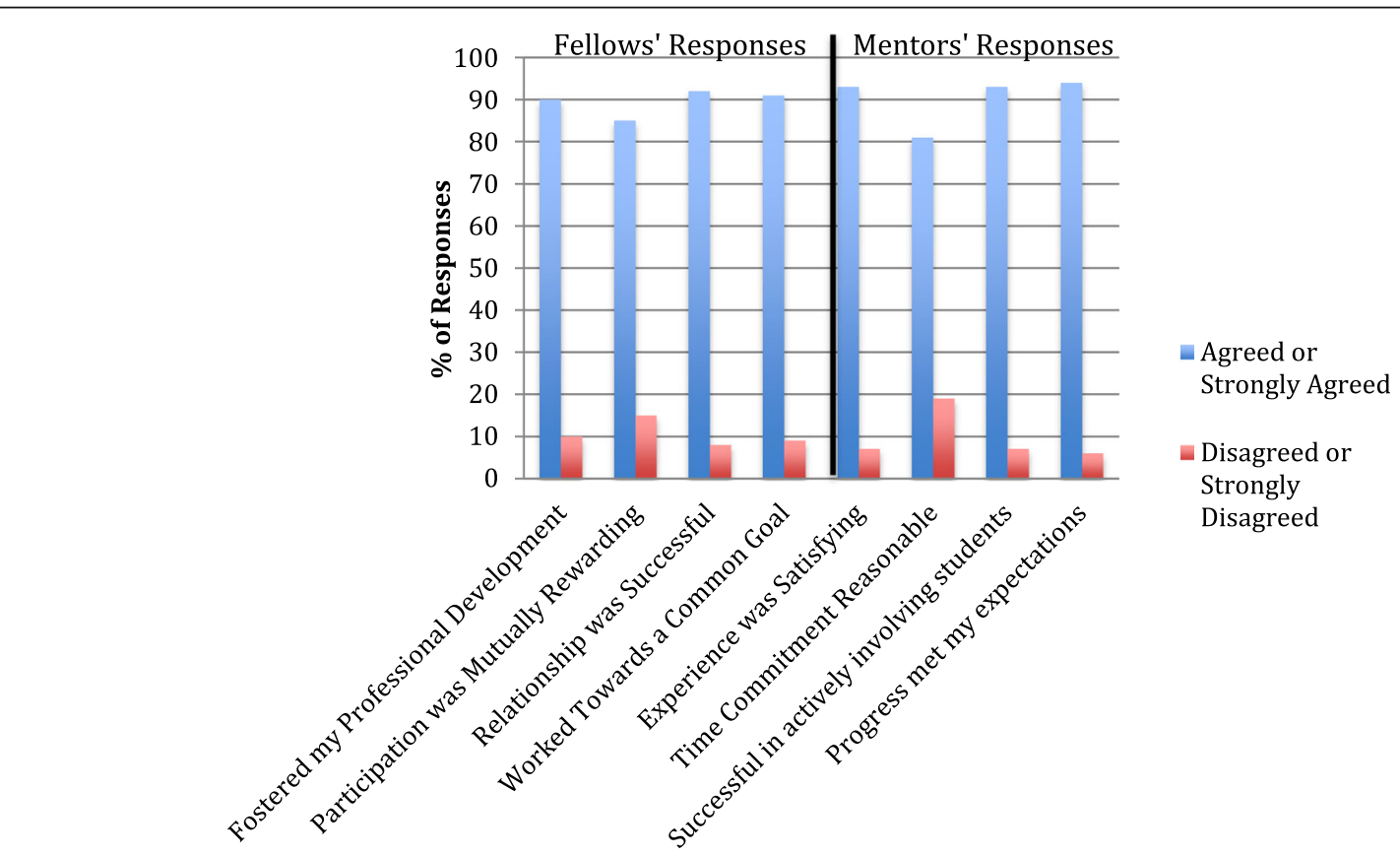

Fig. 3 Mentor and Fellow Satisfaction with Relationship 
ethics and values, and engaging in teamwork [6, 23, 24]. The Fellows engaged in an interprofessional training program that focused on improving students' interprofessional teamwork, communication skills and system-based thinking [25]. The interprofessional education component may have additionally contributed to the improved perception of patient safety competency.

Our findings are limited by the small size of the combined Fellow cohorts $(N=116)$ and the fact that it was conducted at a single academic medical system with a Patient Safety Institute. There was no objective measure of the students' patient safety and quality improvement learning. Furthermore, the Fuld Fellows were selected based on their commitment to patient safety and quality improvement, thus there is selection bias in comparing Fuld and non-Fuld Fellows. It is important to note that eligible students opted not to do Fuld because there were limits on how many extracurricular activities students could partake in, thus non-Fuld Fellows were exposed to other learning opportunities during this time that did not increase their systems thinking and patient safety competencies compared to Fuld Fellows. While Fuld Fellows demonstrated a continued increased in patient safety competencies 1 year following completion of the program, we did not assess non-Fuld Fellows patient safety competencies at the 1 year time point and thus cannot compare the sustained increase. A measure that specifically addresses the role of training in patient safety learning in health professionals' education, such as the Short Version of the Attitudes to Patient Safety Questionnaire [26], may be important to future evaluations of training in patient safety competencies.

Although the curriculum and teaching methodologies for most of the program can be replicated, it may be challenging to find the number and range of knowledgeable and willing mentors in other locations. Faculty time is required as well, one faculty member served as the Fuld faculty for each group of Fellows. The Fuld Faculty had education and training in patient safety and experience in the clinical setting. Responsibilities included instructing the one-credit seminar, and overseeing the mentor-mentee relationship. There were occasional challenges with identifying the right mentor and mentee match, and ensuring that both the Fellow and the mentor were satisfied with the Fellow's level of commitment and time spent on the project. The Fuld faculty helped resolve these issues and assure accountability by making site visits, keeping in touch with mentors by phone or email, solving problems, and meeting with the Fellows in a classroom setting once a month. The selectivity and cohort nature of the Fuld Program also contributed to its success. The Fellows were selected for their interest in patient safety, so their increasing sense of efficacy and positive relationships with mentors was in some part explained by their motivation to apply to the program in the first place.

Further work on programs in health professionals' education specifically focused on patient safety and quality improvement is ongoing and worthwhile. Part of that effort has to be refining and improving evaluation of pre-licensure patient safety education and its impact on health professionals' postgraduate participation and leadership. As the literature grows, faculty will find more evaluation instruments with strong psychometrics to guide streamlining existing program.

\section{Conclusion}

The Fuld Fellows Program effectively introduces a select group of pre-licensure nursing students to essential patient safety and quality improvement concepts. Though all students in the pre-licensure nursing program reported increased patient safety competence, the Fellows reported higher levels of systems thinking and greater improvement in patient safety competence after participation in the program than the pre-licensure students who did not take part in the program. This program can strengthen health professionals' education by offering an academic model and innovative curriculum for building competencies in quality and safety that can be adapted at other institutions.

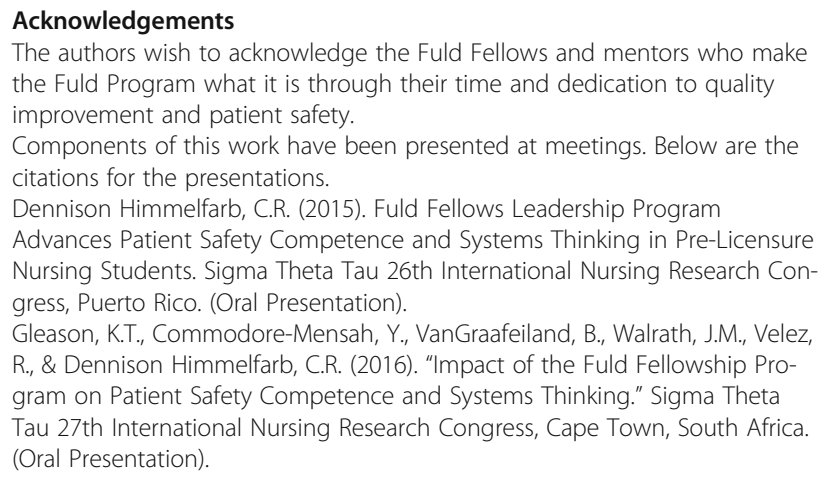

\section{Funding}

The Helene Fuld Health Trust funded the Fuld Fellowship.

\section{Availability of data and materials}

The datasets used and/or analysed during the current study are available from the corresponding author on reasonable request. Details on the Fuld curriculum are available from the corresponding authors, and an overview of the current program is available at: https://nursing.jhu.edu/admissions/ financial-aid/fellowships/fuld/index.html

\section{Authors' contributions}

$\mathrm{KG}, \mathrm{CDH}$, and $\mathrm{YC}$ conceptualized the manuscript and evaluation methods. KG and YC completed the statistical analyses. JW, ER, SI, and BV substantially contributed to the manuscript through feedback to every section, data collection, and writing components of the discussion section. All authors have read and approved the manuscript.

\section{Ethics approval and consent to participate}

Johns Hopkins University School of Medicine Institutional Review Board approved the evaluation methods used for this program (IRB 00087543). The need for informed consent was waived by the IRB.

\section{Consent for publication}

No identifiable individual details, images or videos are reported within this manuscript.

Competing interests

The authors declare that they have no competing interests. 


\section{Publisher's Note}

Springer Nature remains neutral with regard to jurisdictional claims in published maps and institutional affiliations.

\section{Author details}

'School of Nursing, Johns Hopkins University, 525 N Wolfe Street, Baltimore, MD 21205, USA. ${ }^{2}$ Carroll Health Group, Westminster, USA.

Received: 4 April 2018 Accepted: 13 May 2019

Published online: 21 May 2019

\section{References}

1. Street F. Committee on the Robert Wood Johnson Foundation Initiative on the Future of Nursing, at the Institute of Medicine. Medicine (Baltimore) [Internet]. 2010;1-620. Available from: http://www.nap.edu/catalog/12956.html

2. Walton M, Woodward H, Van Staalduinen S, Lemer C, Greaves F, Noble D, et al. The WHO patient safety curriculum guide for medical schools. Qual Saf Heal Care [Internet]. 2010;19(6):542-6. Available from: http://qualitysafety. bmj.com/content/19/6/542.abstract

3. Frank, J.R., Brien S (Ed), Committe. on behalf of the SCS. The Safety Competencies: Enhancing Patient Safety Across the Health Professions [Internet]. Canadian Patient Safety Institute. 2008. Available from: papers:// 07bf99f5-e4dd-47c9-bf40-da9a6d07b924/Paper/p104

4. Nie Y, Li L, Duan Y, Chen P, Barraclough BH, Zhang M, et al. Patient safety education for undergraduate medical students: a systematic review. Vol. 11, BMC Medical Education 2011.

5. Wong BM, Etchells EE, Kuper A, Levinson W, Shojania KG. Teaching quality improvement and patient safety to trainees: a systematic review. Acad Med [Internet]. 2010;85(9):1425-39. Available from: http://www.ncbi.nlm.nih.gov/ pubmed/20543652

6. Ladden MD, Bednash G, Stevens DP, Moore GT. Educating interprofessional learners for quality, safety and systems improvement. J Interprof Care. 2006; 20(5):497-505.

7. Tregunno D, Ginsburg L, Clarke B, Norton P. Integrating patient safety into health professionals' curricula: a qualitative study of medical, nursing and pharmacy faculty perspectives. BMJ Qual Saf [Internet]. 2014;23(3):257-64. Available from: http://qualitysafety.bmj.com/lookup/doi/10.1136/bmjqs2013-001900

8. Berwick DM, Finkelstein JA. Preparing medical students for the continual improvement of Health and Health care: Abraham Flexner and the new "public interest." Acad Med [Internet] 2010;85(1):S56-65.

9. Nursing $\mathrm{AA}$ of $\mathrm{C}$ of. The essentials of baccalaureate education for professional nursing practice. 2008. Washington, DC Author 2010;

10. Ashcraft S, Bordelon C, Fells S, George V, Thombley K, Shirey MR. Interprofessional clinical rounding: effects on processes and Outcomes of care. J Healthc Qual [Internet]. 2016;0(0):1-10. Available from: http://www.ncbi.nlm.nih.gov/pubmed/27310299

11. Carlton EW, Khattab A, Greaves K. Beyond triage: the diagnostic accuracy of emergency department nursing staff risk assessment in patients with suspected acute coronary syndromes. Emerg Med J [Internet]. 2016;33(2): 99-104. Available from: http://emj.bmj.com/lookup/doi/10.1136/emermed2015-204780

12. Dammeyer JA, Mapili CD, Palleschi MT, Eagle S, Browning L, Heck K, et al. Nurse-led change: a statewide multidisciplinary collaboration targeting intensive care unit delirium. Crit Care Nurs Q [Internet] 2012;35(1):2-14. http://www.ncbi.nlm.nih.gov/pubmed/22157488

13. Mount A, Anderson I. Driving change-not just a walk in the park: the role of the nurse champion in sustained change. Nurse Lead. 2015;13(4):36-8.

14. Darsin Singh SK, Ahmad A, Rahmat N, Hmwe NTT. Nurse-led intervention on knowledge, attitude and beliefs towards acute coronary syndrome. Nursing in Critical Care. 2016

15. Kirwan CJ, Wright K, Banda P, Chick A, Mtekateka M, Banda E, et al. A nurseled intervention improves detection and management of AKI in Malawi. J Ren Care. 2016;42(4):196-204

16. Tella S, Liukka M, Jamookeeah D, Smith N-J, Partanen $\mathrm{P}$, Turunen $\mathrm{H}$. What do nursing students learn about patient safety? An integrative literature review. J Nurs Educ [Internet]. 2013;53(1):1-7. Available from: http://www. ncbi.nlm.nih.gov/pubmed/24308538

17. Armstrong G, Barton A. Fundamentally updating fundamentals. J Prof Nurs. 2013;29(2):82-7
18. Bianchi M, Bressan V, Cadorin L, Pagnucci N, Tolotti A, Valcarenghi D, et al. Patient safety competencies in undergraduate nursing students: a rapid evidence assessment. J Adv Nurs. 2016;72:2966-79.

19. Moore S, Dolansky M, Singh M, Plamieri P, Alemi F. The systems thinking scale: a measure of systems thinking. Case west Reserv Univ [Internet]. 2011; 1-27. Available from: http://fpb.case.edu/systemsthinking/

20. Ginsburg L, Castel E, Tregunno D, Norton PG. The H-PEPSS: an instrument to measure health professionals' perceptions of patient safety competence at entry into practice. BMJ Qual Saf [Internet]. 2012;21(8):676-84. Available from: http://qualitysafety.bmj.com/lookup/doi/10.1136/bmjqs-2011-000601

21. Lukewich J, Edge DS, Tranmer J, Raymond J, Miron J, Ginsburg L, et al. Undergraduate baccalaureate nursing students' self-reported confidence in learning about patient safety in the classroom and clinical settings: an annual cross-sectional study (2010-2013). Int J Nurs Stud. 2015;52(5):930-8.

22. Walrath JM, Immelt S, Ray EM, Van Graafeiland B, Dennison Himmelfarb C. Preparing patient safety advocates: evaluation of nursing students' reported experience with authority gradients in a hospital setting. Nurse Educ. 2015; 40(4):174-8.

23. Interprofessional Educational Collaborative, Practice IC, Values U. Core Competencies for Interprofessional Collaborative Practice : 2016 Update. Interprofessional Educ Collab [Internet]. 2016;10-1. Available from: http:// www.ncbi.nlm.nih.gov/pubmed/22030650

24. Leadership S, Technologies H, Outcomes PH, Health I. The essentials of Master's education in nursing. Aacn. 2011:1-64.

25. Aboumatar HJ, Thompson D, Wu A, Dawson P, Colbert J, Marsteller J, et al. Development and evaluation of a 3-day patient safety curriculum to advance knowledge, self-efficacy and system thinking among medical students. BMJ Qual Saf [Internet]. 2012;21(5):416-22. Available from: http:// qualitysafety.bmj.com/lookup/doi/10.1136/bmjqs-2011-000463.

26. Kiesewetter J, Kager M, Fischer MR, Kiesewetter I. German short version of the attitudes to patient safety questionnaire subscale composition. GMS J Med Educ. 2017;34(1).

Ready to submit your research? Choose BMC and benefit from:

- fast, convenient online submission

- thorough peer review by experienced researchers in your field

- rapid publication on acceptance

- support for research data, including large and complex data types

- gold Open Access which fosters wider collaboration and increased citations

- maximum visibility for your research: over $100 \mathrm{M}$ website views per year

At BMC, research is always in progress.

Learn more biomedcentral.com/submissions 